\title{
O Efeito Chicote e a Dinâmica de Cadeia de
}

\section{Suprimentos}

\section{Resumo}

Este ensaio pretende abordar as relações entre empresas numa cadeia de abastecimento. Adicionalmente, espera colaborar como um roteiro bibliográfico inicial visando a uma estruturação de conhecimento para futuros trabalhos. $\mathrm{O}$ artigo descreve como o bullwhip effect (ou efeito Forrester) influencia a cadeia de suprimento de bens de consumo. Mostra o processo dinâmico de abastecimento, desde fornecedor de matériaprima até a venda de bens para o varejista, passando pelo fabricante (OEM) e distribuidores. $\mathrm{O}$ texto focaliza o empenho das empresas em tentar coordenar as ações na cadeia de suprimentos de modo que seus esforços estejam alinhados para um mesmo propósito e não mais como um vetor de resultante zero. Apresenta as bases do VMI e os resultados gerais obtidos por uma montadora de automóveis dentro da rede de peças de reposição para veículos nas oficinas de serviço.

\section{Abstract \\ This assay approaches the relations between companies in a supplying chain. Additionally, collaborate as an initial bibliographical route aiming at to get structured of knowledge for future works. The article describes as bullwhip effect (or Forrester effect) influences the supplying chain of consumption good. It shows the dynamic process of supplying,}

since raw material supplier until vendor of good for the retailer, passing for the manufacturer (OEM) and deliverers. The text focuses the persistence of the companies in trying to co-ordinate the supplying chain actions and its efforts to be lined up in same intention, not more a vector of resultant zero. Presents the bases of the VMI and the general results gotten by an automobile-assembly plant inside network supplying spare parts in the custom service.

\section{Introdução}

A viabilidade do abastecimento de mercados consumidores é atribuída a uma complexa e interligada cadeia de fornecedores e clientes, por onde fluem materiais, produtos, informações e dinheiro. Nota-se, dentro da gestão de operações, "um desbalanceamento entre o tratamento de operações dentro dos nós da rede de suprimentos e entre os nós da rede de suprimentos" (CORRÊA, 1999). Apenas ultimamente a área de gestão de operações passou a dar mais destaque sobre as questões de como tratar as relações entre empresas. Esta abordagem parte da utilização através do modelo de aprendizagem organizacional apresentado pelos pesquisadores do MIT (Massachusets Institute of Technology), preconizado por Jay Forrester.

Este ensaio pretende abordar as relações entre empresas numa cadeia de abastecimento. Adicionalmente, espera colaborar como um ro-

\footnotetext{
1 Pós-graduado em Adminisrtação de Negócios pelo Mackenzie, MBA profissionalizante pela FGV-Siemens, Mestre em Administração de Empresas, professor das Faculdades Integradas "Campos Salles" e gerente de produção e logística da Siemens Ltda.

E-mail: lino.gaviolli@siemens.com

2 Doutor em Comunicação e Semiótica e Mestre em Administração pela PUC-SP. Pesquisador e Professor da Universidade Braz Cubas e das Faculdades Integradas "Campos Salles".

E-mail: mauro.laruccia@terra.com.br
} 
teiro bibliográfico inicial visando a uma estruturação de conhecimento para futuros trabalhos, e ainda oferecer uma argumentação, ainda que preliminar, sobre as dificuldades em coordenar uma rede de suprimentos. Destaca, também, as relações da cadeia de suprimentos imediata, ou seja, onde estão os fornecedores e consumidores com os quais a empresa faz negócios diretamente, e traz, também, preocupações das OEM's (Original Equipment Manufacturer) em coordenar o negócio entre os elos da cadeia, como mostra o estudo de caso da General Motors no Brasil e alguns dos resultados obtidos na coordenação da rede de abastecimento.

\section{A Rede de Suprimentos e o Consumidor Final}

Antes, porém, de serem apresentadas as características da indústria automobilística, tida como referência válida para analisar os avanços no gerenciamento de cadeias de suprimento, será apresentado um rápido relato sobre o propulsor do pensamento sistêmico.

Durante a II Guerra Mundial, o engenheiro elétrico Jay W. Forrester, juntamente com outros técnicos do laboratório de servomecanismos do MIT, realizavam trabalhos para as forças armadas americanas, através do desenvolvimento de controles para armas e radares. Em 1956, Forrester dedicou-se às aplicações de dinâmica a problemas administrativos.

A partir destes trabalhos, Forrester escreveu o livro "Industrial Dynamics" em 1961, que dá origem à Dinâmica de Sistemas. A aplicação destes conhecimentos a problemas sociais e administrativos ocorreu posteriormente com a edição do livro "Urban Dynamics" e mais tarde com o livro "World Dynamics". É justamente destes trabalhos que se desenvolve o conceito sobre o bullwhip effect (ou efeito Forrester) dentro das redes de suprimentos.

Apenas como ilustração, foi participando destes empreendimentos e tendo Forrester como orientador, que o engenheiro Peter M. Senge começou a desenvolver as relações sobre o aprendizado organizacional.

\section{A Cadeia de Suprimentos}

De acordo com Slack et al. (2002), as cadeias de suprimento podem ser vistas em três grandes níveis. A cadeia de suprimentos total é aquela que envolve todas as relações cliente-fornecedor, desde a extração da matéria-prima até a compra do produto pelo consumidor final. A cadeia de suprimentos imediata, como foi dito anteriormente, é aquela em que estão os fornecedores e consumidores com os quais a empresa faz negócios diretamente. Num terceiro nível ocorrem as transações dentro da própria empresa, com fluxos internos de materiais e informações dentre departamentos e setores produtivos.

Nesta conjuntura vale ressaltar o papel dos gerentes de produção e operações, cuja história mostra que sempre focalizam (e de modo intenso) suas próprias unidades produtivas, ou seja, apenas o terceiro nível da cadeia de suprimentos. Contudo, cada vez mais devem ultrapassar esta visão interna à empresa para gerenciar suas atividades de forma mais eficaz. Em nível estratégico, os gerentes de produção deveriam estar mais envolvidos em projetar a forma da rede na qual a operação está inserida. Vale lembrar que materiais, produtos, informações, valores e serviços fluem pela rede de relações cliente-fornecedor formada por estas operações, como mostrado na figura 1 a seguir: 


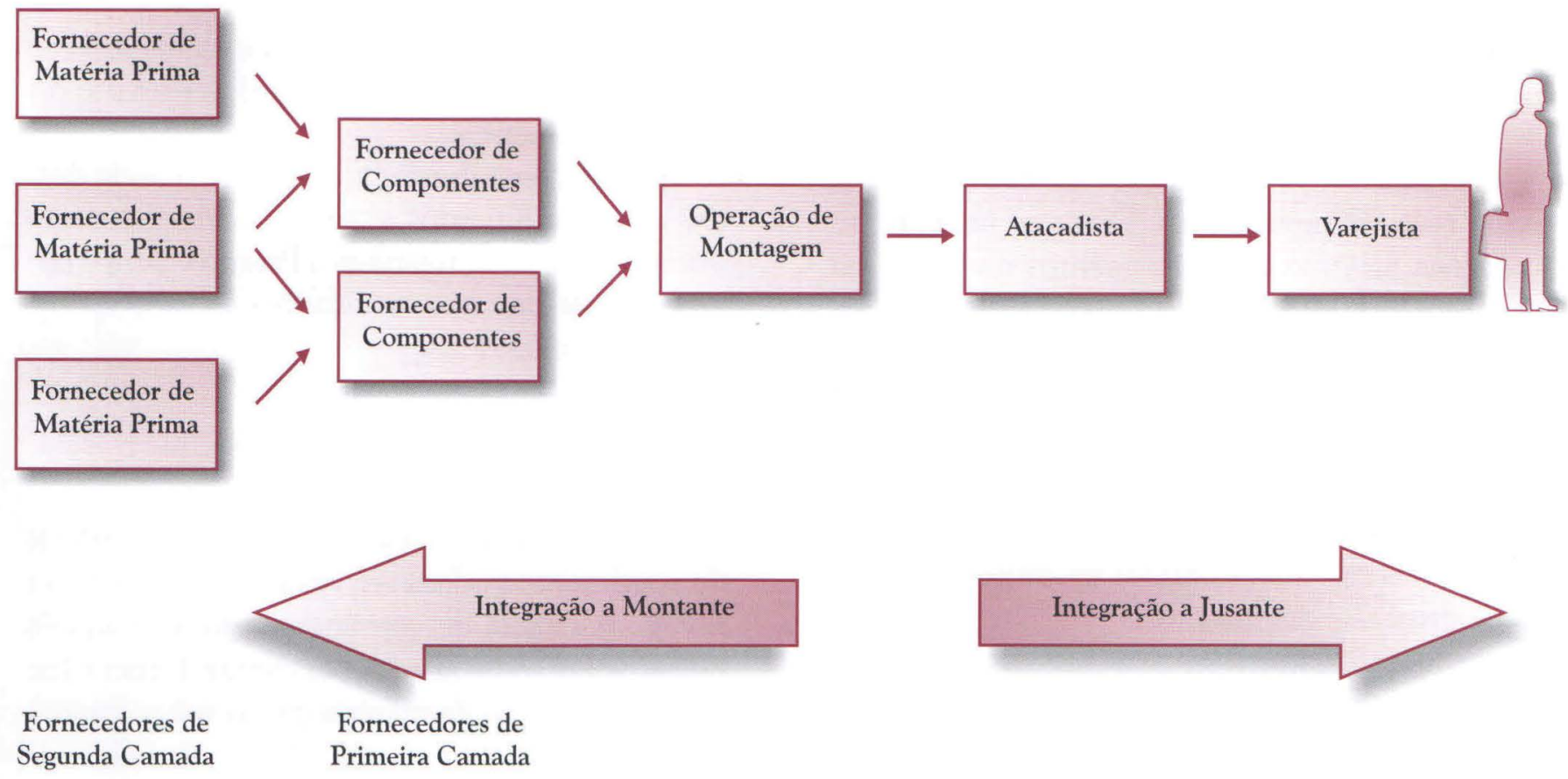

Figura 1. Direção e amplitude de uma rede de suprimentos (Slack et al., 2002).

Ressaltando-se o lado da demanda (a jusante da operação de montagem) o fabricante fornece produtos a atacadistas, que fornecem aos pontos de venda varejistas e estes, por sua vez, ao cliente final. No sentido inverso, cada elo enviará informações para seus fornecedores (na forma de pedidos). Assim, quando o estoque reduzir à jusante da cadeia, os varejistas farão pedidos ao atacadista (ou eventualmente diretamente ao fabricante); da mesma forma, o atacadista fará pedidos ao fabricante e este a seus fornecedores. É um processo de mão dupla, com bens fluindo em um sentido e informações no sentido oposto.

Segundo Slack et al. (2002) "a gestão da cadeia de suprimentos é a gestão da interconexão das empresas que se relacionam por meio de ligações à montante e a jusante entre os diferentes processos, que produzem valor na forma de produtos e serviços para o consumidor final." Diferentemente da visão mecanicista apontada por Weber, esta abordagem holística proposta por Slack aponta na direção de que existem benefícios substanciais a serem ganhos ao administrar-se a cadeia de operações de modo que satisfaçam ao consumidor final.

Observando-se a figura 1 é possível notar que cada player da rede toma para si parte do dinheiro que recebe da venda dos produtos e serviços para pagar seus custos, garantir o retorno sobre seu investimento e repassa o restante, na forma de pagamento pelos materiais e serviços que adquire dos fornecedores imediatos. A única exceção é o usuário final: ele é o único "alimentador" da rede quanto a valores monetários, ou seja, é o único que possui moeda real na cadeia de suprimentos, quando decide fazer uma compra e, portanto, disparar centenas de ações ao longo de toda a cadeia.

A figura 2 a seguir demonstra esta situação. 


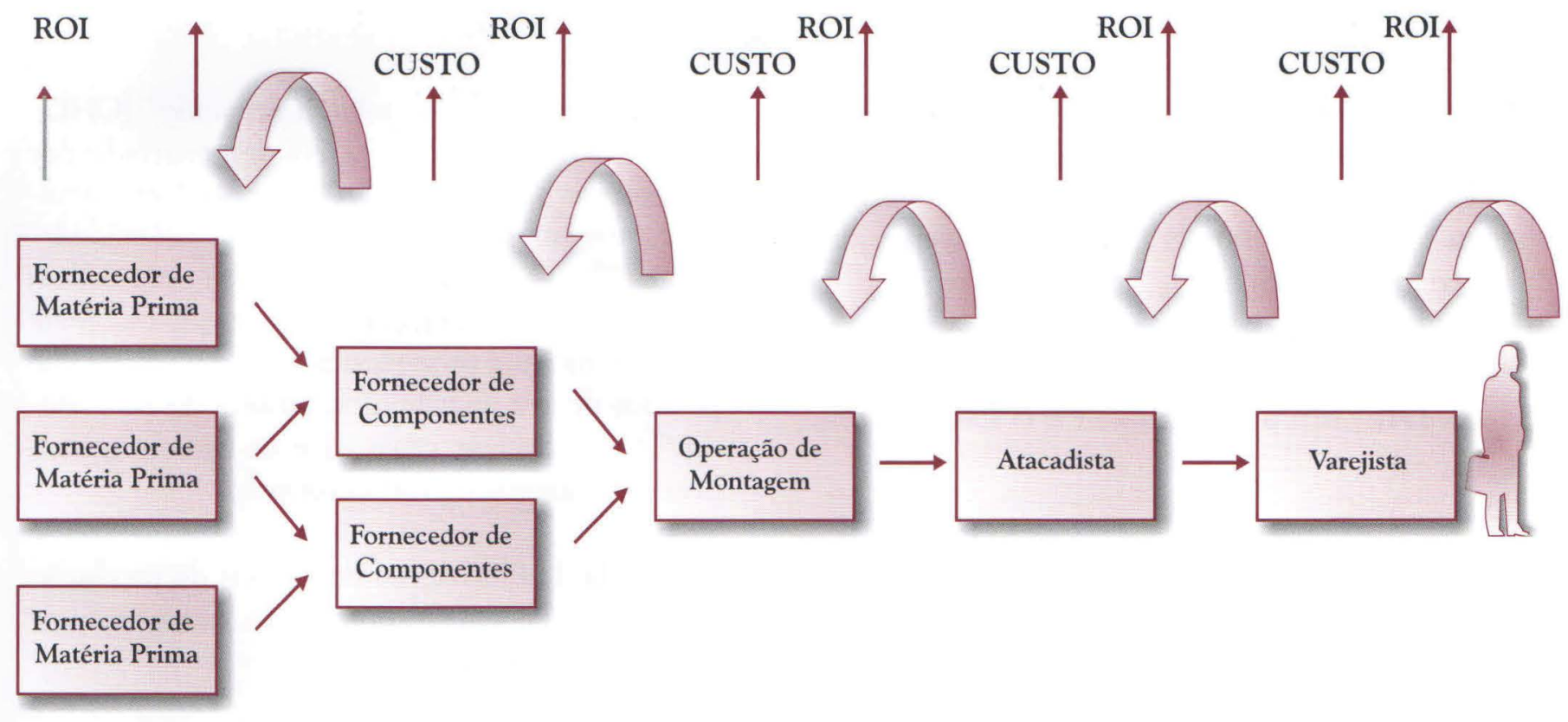

Figura 2- Fluxo de valores dentro da cadeia de suprimentos (fonte: dos autores).

\section{A Previsão de Demanda e a Coordenação da Cadeia de Abastecimento}

Segundo Bowersox \& Closs (2001), "o planejamento e o controle da logística exigem a melhor estimativa possivel das quantidades de itens demandadas por local (SKU), embora a tarefa de previsão não seja totalmente uma ciência básica". No lastro desta afirmação, muitas empresas têm adotado processos integrados de previsão, que incluem coleta de dados de diversas fontes e apuradas técnicas matemáticas.

Não obstante, a importância do pessoal para a atividade é fundamental, não apenas do grupo de disposição de produtos, treinado com fortes bases teóricas e motivado para a tarefa, mas também (e especialmente) a integração do time de vendas neste processo - se os setores envolvidos nesta atividade não estiverem focados num só objetivo (o cliente final), os cálculos matemáticos usados para transformar dados históricos em quantidades futuras continuarão sendo importantes, mas seu sucesso será questionável. Neste contexto, uma sistemática para suporte às previsões deve abranger a capacidade de coleta e análise de dados históricos e permitir a consideração de fatores externos como promoções, alterações de preços e as oscilações do comportamento do mercado e da concorrência. Logo, nota-se que a gestão da previsão de demanda não é tarefa fácil, ao contrário, requer grande envolvimento e espírito crítico dos profissionais relacionados com a atividade.

Previsões isoladas podem incorrer em resultados menores para a cadeia (ou até negativos). "A coordenação da cadeia de suprimentos melhora se todos os estágios realizarem ações que, em conjunto, aumentem os lucros totais da cadeia de suprimento" (CHOPRA \& MEINDL, 2003). A afirmação introduz o conceito de que o arranjo da cadeia de suprimentos exige que cada estágio leve em consideração o impacto que suas ações exercem sobre os outros elos. Há falta de coordenação quando cada elo procura maximizar os seus próprios lucros e não necessariamente da cadeia como um todo. Assim, embora os esforços sejam grandes, sua soma vetorial poderá ser nula.

Uma outra razão da dificuldade de coordenação da cadeia ocorre devido ao fato das informações serem distorcidas ao longo da cadeia. A Ford, por exemplo, detém dezenas de fornecedores, desde pneus Goodyear, passando pelos relês eletrônicos Siemens, aos amortecedores Cofap e cada fornecedor possui diversos outros fornecedores. As informações vão sendo distorcidas à 
medida que circulam pela cadeia. O desafio hoje não é, portanto, competir isoladamente no mercado, mas que as cadeias atinjam coordenação, apesar do grande número de responsáveis e da variedade de produtos.

\section{A Dinâmica da Cadeia e o Efeito} Chicote

Muitas empresas observaram o efeito chicote, em que a variabilidade é ampliada em cada elo da cadeia de suprimento. Isto distorce as informações na cadeia, "levando estágios diferentes a fazer análises muito distintas sobre a demanda" (CHOPRA \& MEINDL, 2003). Foi demonstrado por Jay Forrester, nos anos 60, que existe "certa dinâmica entre empresas, que causa erros e volatilidade" (SLACK ET AL., 2002). Suponha uma cadeia bastante simplificada, como a mostrada na tabela a seguir, na qual uma montadora (OEM) recebe pedidos de seu distribuidor, através do revendedor (ou oficina de reparos) e os repassa para a primeira camada de fornecedores.

Tabela 1. Flutuações dos níveis de produção ao longo da cadeia de suprimento. (adaptação de Slack et al., 2002).

\begin{tabular}{|c|c|c|c|c|c|c|c|c|c|}
\hline PER. & \multicolumn{2}{|c|}{ Fornecedor } & \multicolumn{2}{|c|}{ OEM } & \multicolumn{2}{|c|}{ Distribuidor } & \multicolumn{2}{|c|}{ Revendedor } & Merc. \\
\hline \multirow{4}{*}{1} & Est. Ini. & 100 & Est. Ini. & 100 & Est. Ini. & 100 & Est. Ini. & 100 & \multirow{4}{*}{100} \\
\hline & Dem. & 100 & Dem. & 100 & Dem. & 100 & Dem. & 100 & \\
\hline & Prod. & 100 & Prod. & 100 & Compra & 100 & Compra & 100 & \\
\hline & Est. Fin. & 100 & Est. Fin. & 100 & Est. Fin. & 100 & Est. Fin. & 100 & \\
\hline \multirow{4}{*}{2} & Est. Ini. & 100 & Est. Ini. & 100 & Est. Ini. & 100 & Est. Ini. & 100 & \multirow{4}{*}{95} \\
\hline & Dem. & 60 & Dem. & 80 & Dem. & 90 & Dem. & 95 & \\
\hline & Prod. & 20 & Prod. & 60 & Compra & 80 & Compra & 90 & \\
\hline & Est. Fin. & 60 & Est. Fin. & 80 & Est. Fin. & 90 & Est. Fin. & 95 & \\
\hline \multirow{4}{*}{3} & Est. Ini. & 60 & Est. Ini. & 80 & Est. Ini. & 90 & Est. Ini. & 95 & \multirow{4}{*}{95} \\
\hline & Dem. & 120 & Dem. & 100 & Dem. & 95 & Dem. & 95 & \\
\hline & Prod. & 180 & Prod. & 120 & Compra & 100 & Compra & 95 & \\
\hline & Est. Fin. & 120 & Est. Fin. & 100 & Est. Fin. & 95 & Est. Fin. & 95 & \\
\hline \multirow{4}{*}{4} & Est. Ini. & 120 & Est. Ini. & 100 & Est. Ini. & 95 & Est. Ini. & 95 & \multirow{4}{*}{95} \\
\hline & Dem. & 90 & Dem. & 95 & Dem. & 95 & Dem. & 95 & \\
\hline & Prod. & 60 & Prod. & 90 & Compra & 95 & Compra & 95 & \\
\hline & Est. Fin. & 90 & Est. Fin. & 95 & Est. Fin. & 95 & Est. Fin. & 95 & \\
\hline \multirow{4}{*}{5} & Est. Ini. & 90 & Est. Ini. & 95 & Est. Ini. & 95 & Est. Ini. & 95 & \multirow{4}{*}{95} \\
\hline & Dem. & 95 & Dem. & 95 & Dem. & 95 & Dem. & 95 & \\
\hline & Prod. & 100 & Prod. & 95 & Compra & 95 & Compra & 95 & \\
\hline & Est. Fin. & 95 & Est. Fin. & 95 & Est. Fin. & 95 & Est. Fin. & 95 & \\
\hline \multirow{4}{*}{6} & Est. Ini. & 95 & Est. Ini. & 95 & Est. Ini. & 95 & Est. Ini. & 95 & \multirow{4}{*}{95} \\
\hline & Dem. & 95 & Dem. & 95 & Dem. & 95 & Dem. & 95 & \\
\hline & Prod. & 95 & Prod. & 95 & Compra & 95 & Compra & 95 & \\
\hline & Est. Fin. & 95 & Est. Fin. & 95 & Est. Fin. & 95 & Est. Fin. & 95 & \\
\hline
\end{tabular}


Inicialmente, a demanda está estabilizada em 100 peças por período, como mostrado na Tabela 1. No segundo período, a demanda é reduzida para 95 unidades - o exemplo é bastante corriqueiro, pois muitas empresas mantêm seus níveis de estoque ajustados à demanda do período. Assim, o revendedor que possuía 100 unidades em estoque, percebe a demanda de 95 unidades e libera um pedido de 90 peças ao distribuidor, uma vez que junto com as cinco outras unidades restantes do estoque inicial, irá suprir a demanda e deixar o estoque final em 95 peças. Por sua vez, o distribuidor regional faz um pedido de 80 unidades à fábrica, já que sobraram 10 unidades de seu estoque inicial e seu objetivo é manter estoques equiparados à demanda percebida, neste caso, 90 peças. $O$ produtor, percebendo a demanda de 80 unidades, entende que deve dispa-

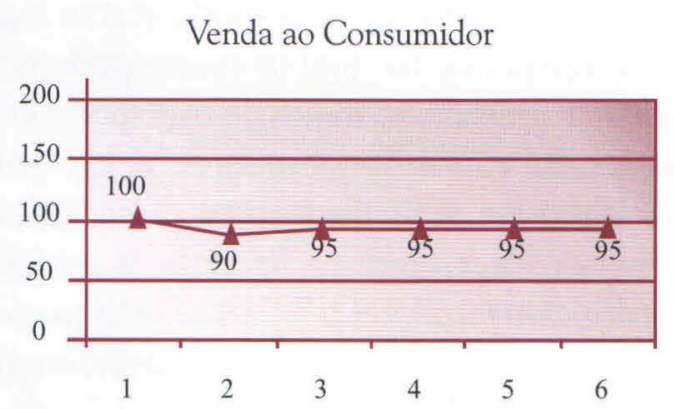

Pedidos do Distribuidor ao Fabricante

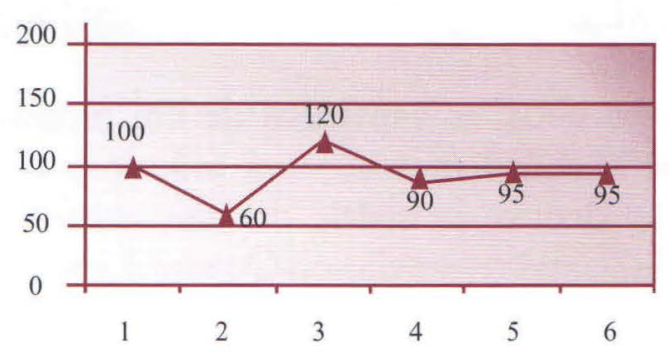

rar um pedido de 60 unidades para nivelar seus estoques, dada a sobra de produtos no período. Seguindo o mesmo raciocínio, o fornecedor da primeira camada deverá produzir apenas 20 peças, de modo a equiparar seu estoque à demanda recebida (uma redução de $80 \%$ da quantidade original no mesmo período, em comparação a $5 \%$ de variação pelo cliente final).

Neste período há sobre-estoque em toda a cadeia, gerando capacidades ociosas e, portanto, custos desnecessários. Ao se analisar o período seguinte, mesmo mantendo-se constante a demanda inicial do mercado consumidor, haveria falta de produtos em praticamente todos os elos da cadeia, gerando horas extras e novamente custos inúteis. $\mathrm{O}$ fornecedor deverá alterar a produção em $900 \%$. Os gráficos da figura 3 a seguir mostram esta situação.

Pedidos do Varejista ao Distribuidor

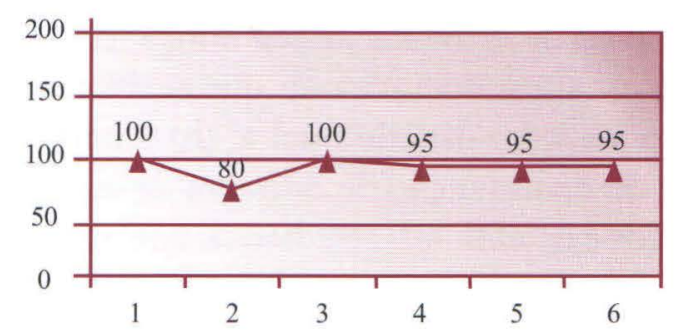

Pedidos do Fabricante ao Fornecedor

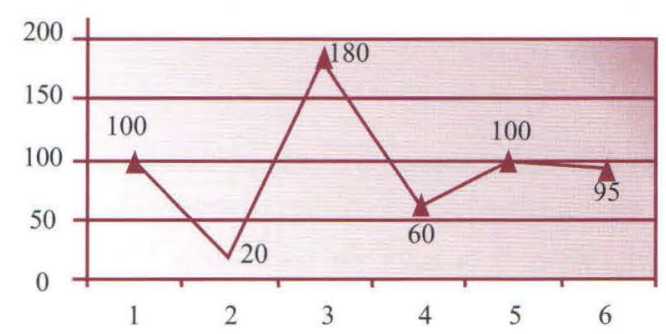

Figura 3- Flutuações da demanda em diferentes elos da cadeia de suprimentos (adaptação de Chopra \& Meindl, 2003).

As conseqüências do bullwhip effect, mostrado acima, são mais acentuadas se considerarmos a defasagem de tempo entre a ocorrência da demanda em determinada parte da cadeia e sua transmissão para o elo seguinte. Na realidade, este delta de tempo fará com que as flutuações sejam ainda maiores. Para além disso, na prática este efeito é potencializado quando diferentes pedidos são recebidos por diferentes elos em momentos aleatórios. O resultado é uma enorme instabilidade nos programas de produção nas empresas a montante da rede, gerando horas ex- 
tras quando o efeito chicote oscila para cima, e pagar (caros) períodos de ociosidade quando o chicote oscila para baixo.

Além das simplificações comentadas, o exemplo acima não pondera lotes mínimos e múltiplos de produção, bastante comuns nas empresas, o que poderia causar mais distorções, fazendo com que os volumes de produção variassem muito mais fortemente nos fornecedores à montante da rede.

Em seu artigo "General Motors Brazil Service Business" o Prof. Henrique Corrêa mostrou claramente duas fortes implicações para os elos da cadeia de abastecimento, que em maior ou menor grau são: (a) a demanda oscilante com amplitude alta não é previsível, pois se trata do resultado do efeito somado de uma grande quantidade de variáveis fora de controle. Para uma empresa atender seus clientes com altos níveis de serviço e simultaneamente alta incerteza de demanda futura, é necessário que trabalhe com altos níveis de estoques de segurança, o que aumenta os custos operacionais que acabam sendo repassados até o usuário final e, (b) a impossibilidade de manutenção de estoques de segurança tão altos nos elos intermediários que garantam altos níveis de disponibilidade no ponto de venda faz com que os níveis de serviço ao usuário final caiam (CORREAA, 2001).

\section{O Modelo Vendor Managed Inventory}

Uma das soluções possíveis para atenuar e, em alguns casos eliminar o efeito chicote descrito no item anterior, é o uso de modelos V.M.I. (Ven- dor Managed Inventory) de gestão de estoques na rede de suprimentos.

A agilidade no fluxo de informações trafegando pela rede é uma das colunas do VMI. Depois de a demanda no revendedor ter sido reduzida para 95 peças, como no exemplo que discutimos, o bullwhip effect, se os elos a montante da rede pudessem saber disso de imediato e ajustassem seus níveis de estoques para este novo nível da ponta do varejo, talvez num só período, todos os elos estivessem com seus novos níveis de estoques sem grandes variações de demanda.

Por exemplo, um fabricante que fornece produtos para diversos distribuidores regionais conhece a demanda nacional de seus produtos muito melhor que qualquer um de seus distribuidores. Este elo forte da cadeia de suprimentos é capaz de fazer previsões de demanda muito mais acertadamente que qualquer dos distribuidores. Desta forma, é possível se fazer uma gestão logística mais adequada, na qual os custos podem ser reduzidos, utilizando-se meios de transporte consolidados para vários distribuidores, e, portanto, fazendo entregas mais freqüentes e em quantidades menores por produto, levando os estoques médios dos distribuidores a níveis reduzidos, com conseqüentes aumentos do grau de atendimento ao mercado.

\section{Vantagens e Restrições para o Sucesso do V.M.I.}

Como visto, as vantagens de um programa Vendor Managed Inventory em reduzir o efeito bullwhip dentro da cadeia de suprimentos são grandes, como resumidas no Quadro 1 a seguir. 


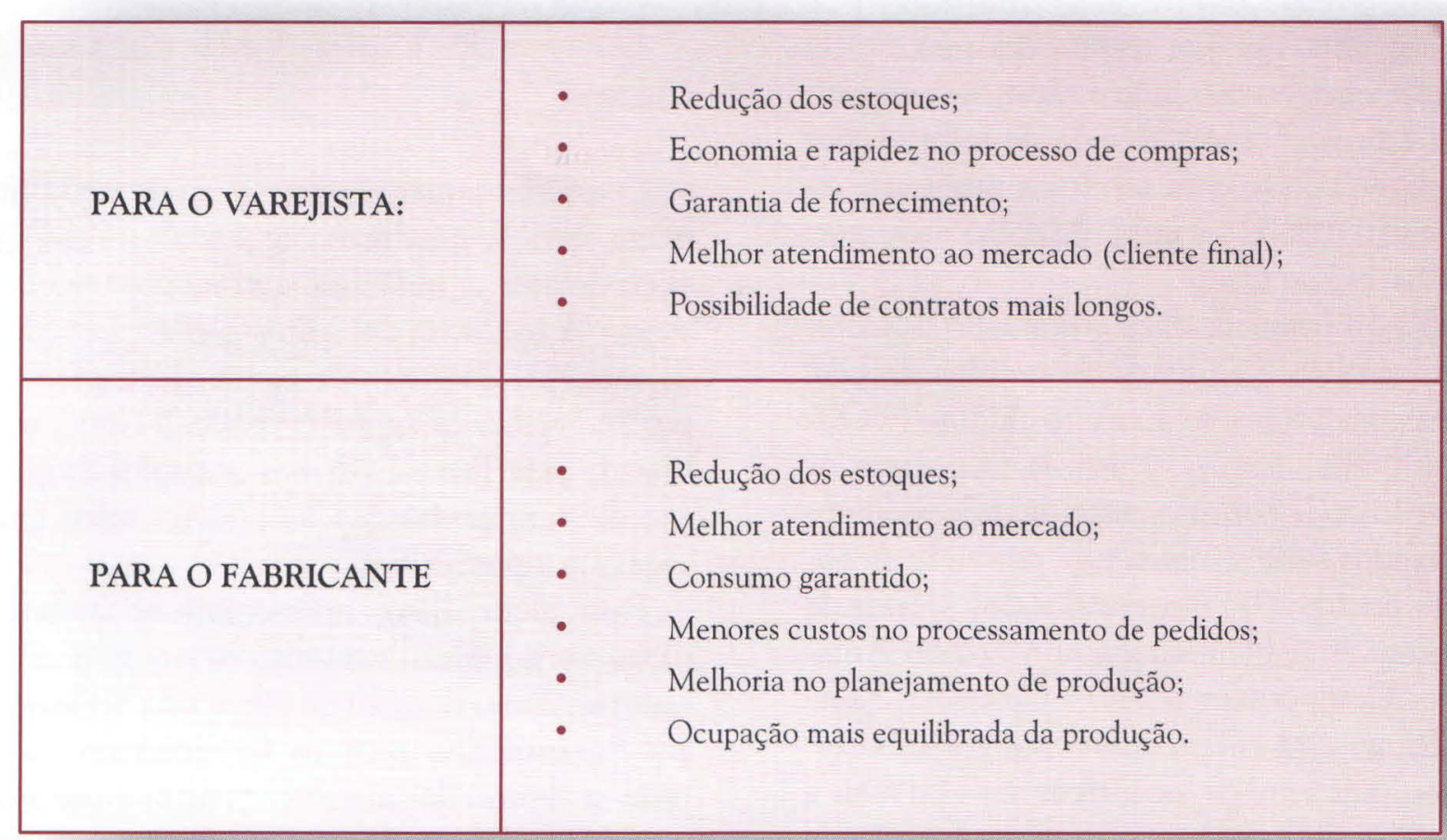

Quadro 1- Vantagens da redução do efeito Forrester na cadeia de abastecimento (fonte: dos autores).

Enquanto os benefícios são bastante visíveis, as desvantagens estão muitas vezes implícitas e só percebidas quando da operacionalização do conceito. Embora a iniciativa de gerenciamento da rede esteja a cargo do elo forte da cadeia, este (que tem maior probabilidade de êxito) tem pouco interesse em disparar iniciativas de gestão de rede, visto que não é aparentemente o maior beneficiário, pelo menos no curto prazo.

Outra possível desvantagem do VMI é que os varejistas, muitas vezes, vendem produtos de outros fabricantes, concorrentes da mesma marca. Do ponto de vista do cliente final, tais produtos são substituíveis.

Muito além das relações entre empresas ou da tecnologia de redes e captura de dados para serem transformados em informações fidedignas, o desenvolvimento đa confiança nos negócios passa a ser um dos fundamentos para o sucesso de qualquer projeto empresarial, quer nas relações entre empresas ou mesmo no ambiente interno de trabalho. Quanto mais a empresa utiliza tecnologias para transações à distância, maior será a necessidade de contato e transparência entre as pessoas.

Seja qual for a intensidade das alianças entre empresas, ser um bom parceiro tem se tornado crescentemente um fator crítico de sucesso (ou de sobrevivência futura). Para que esta vantagem colaborativa ocorra, tais alianças devem trazer benefícios para todos os parceiros, criação conjunta de valor (mais do que exclusivamente troca) e serem controladas através de infra-estrutura que possibilite e aumente o aprendizado das partes componentes desta aliança. Aqui a relação de confiança é construída de forma lenta, mas sustentada e progressivamente. A base de todo o sucesso do relacionamento entre as empresas neste modelo é a cooperação.

\section{Ações para Atingir a Coordenação da Rede}

Além da série de ações propostas pelo VMI, outras medidas gerenciais em conjunto certamente colaboram para atenuar o bullwhip effect, como por exemplo:

Lead Time. As empresas têm que reduzir os tempos de reposição dos produtos. Esta é uma tarefa árdua, contendo diversas facetas envolvidas, mas que deve ser perseguida por todos os elos 
da cadeia, uma vez que resulta em maior grau de atendimento ao mercado e reduções substanciais de custos. A transferência de informações do ponto de venda para os elos a montante da cadeia via EDI pode ser utilizada como meio para a redução de lead times.

Pedidos em Lotes. Reduzir o tamanho dos lotes e promover maior freqüência de pedidos também colabora para a redução do efeito chicote (DORNIER, ET. AL., 2000). O uso de tecnologia de informação pode cortar o custo de processamento de pedidos substancialmente, por meio da eliminação do trabalho em papel e dos pontos de verificação. A implementação do Pedido Auxiliado por Computador (CAO - Computer Assisted Ordering) está em progresso nas grandes corporações, pois fornece incentivos aos elos mais a jusante da cadeia pedirem com maior freqüência (e, portanto, em menores quantidades).

Flutuação de Preços. Promoções e descontos por quantidades também aumentam a variabilidade das médias consumidas. A estratégia mais simples é reduzir a magnitude destes acordos comerciais. Neste sentido, muitos fabricantes mudaram a estratégia para "preço baixo todos os dias"; isto denota a mudança de descontos por quantidade baseados no tamanho do lote para descontos baseados em volumes ao longo do tempo.

No Brasil há ainda a dificuldade quanto às distâncias geográficas substanciais a serem vencidas. Isto implica em lead times maiores, por transportes mais longos. Ao invés de compensar com estoques maiores, a maior freqüência de pedidos poderia colaborar para atenuar este efeito, atrelada a entregas consolidadas que também impediriam o aumento de custos com fretes.

Todas essas medidas estão no sentido de atenuar os efeitos bullwhip, mas seus resultados podem ser questionáveis se não houver um esclarecimento bastante amplo das razões do uso VMI, não apenas internamente à organização, como entre os elos da cadeia, de modo a fomentar a confiança e conquistar o comprometimento dos colaboradores neste desafio. $\mathrm{O}$ estudo de caso mostra esta preocupação da montadora GM no Brasil.

\section{Estudo de Caso: VMI na General Motors}

$\mathrm{O}$ estudo requer mostrar quais as razões para maior atenção à indústria de veículos. Peter Drucker definiu a indústria automobilística como sendo "a indústria das indústrias": a introdução de conceitos de produção em massa, capitaneada por H. Ford, o conceito de produção enxuta, delineado pela Toyota, são dois exemplos da produção de automóveis que inovaram outros tantos segmentos produtivos.

Para além disso, apresentam-se iniciativas pioneiras no relacionamento montadoras-fornecedores, como no caso da fábrica da Volkswagen em Resende (no qual os fornecedores encontram-se dentro das instalações de montagem dos veículos), mas também especialização da força de trabalho, aumento da capacidade produtiva e instalação de empreendimentos automobilísticos em áreas tradicionalmente sem expressão neste setor industrial. Estas iniciativas estão calcadas em diversos fatores como a entrada de novos players no mercado brasileiro, a guerra fiscal entre Estados, a forte desvalorização da moeda brasileira ocorrida entre 1999 e 2002, o acordo automotivo do bloco Mercosul, o tímido avanço do país como pólo exportador de automóveis, além das freqüentes oscilações ocorridas nas vendas internas nos últimos anos.

Na última década tem-se apontado para um modelo em que os fornecedores assumem cada vez mais funções de agregação de valor, enquanto que as montadoras assumem uma função de coordenação e gerenciamento desta cadeia.

\section{A Cadeia de Autopeças}

É importante observar a cadeia de suprimentos onde se insere o caso em questão. Como vimos, as cadeias de suprimento são sistemas dinâmicos.

É quase padrão no mercado existir fabricantes automotivos que servem a dois grupos de clientes finais, com necessidades significativamente diferentes entre si: o consumidor de automóveis e o consumidor que adquire peças sobressalentes para os veículos, conforme ilustra a Figura 4. 


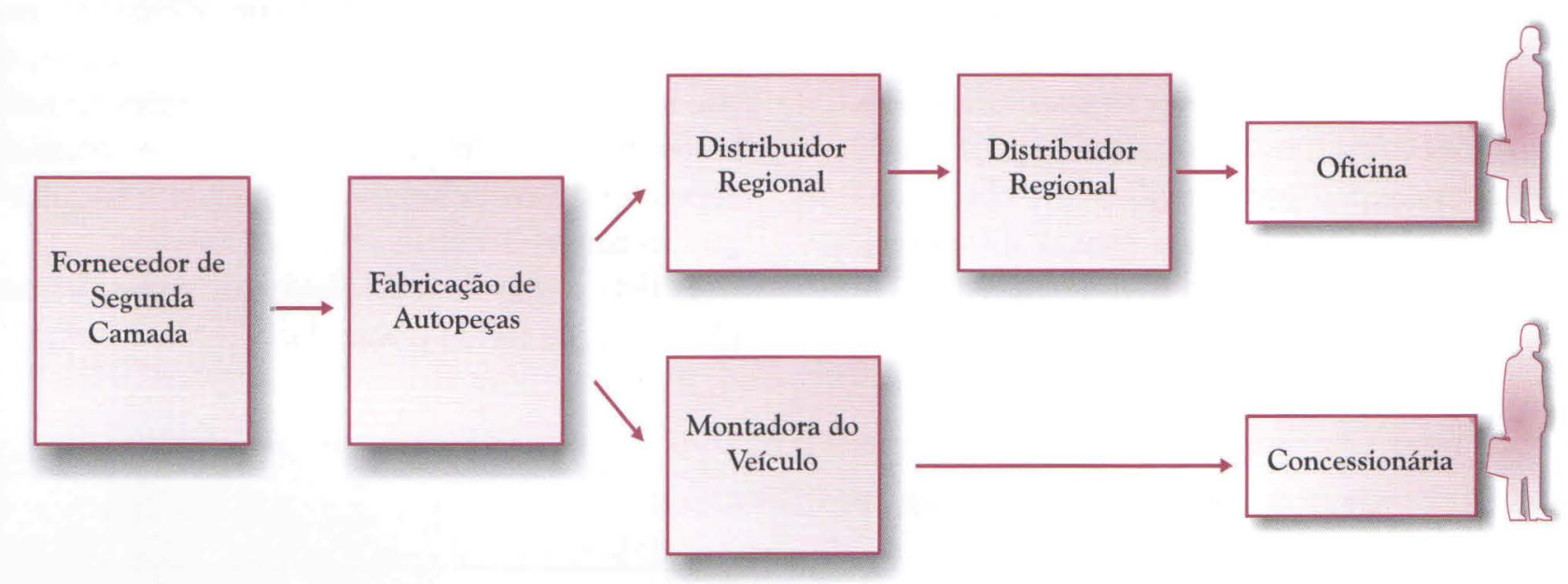

Figura 4- O fabricante de autopeças e dois grandes segmentos de mercado com necessidades distintas (fonte: dos autores).

No ramo da produção de veículos, a qualidade e o preço são fatores críticos de sucesso para o negócio, porém, no segmento de autopeças as necessidades apontam para alta disponibilidade e variedade de itens (lembrando que o mercado precisa reparar veículos com 10 ou 15 anos de uso). Geralmente os consertos devem ser feitos em um ou dois dias, o que torna a situação mais crítica, devido à falta de previsão da peça para o reparo.

Um exemplo são os recentes acordos de reposição automática entre a GM com sua rede de concessionárias, para uma gestão mais racional dos fluxos de produtos.

\section{A Escolha da General Motors: Uma Ruptura com o Passado}

O estudo de caso se prende à cadeia de partes e peças de reposição fornecidas para as oficinas de reparos, procurando descrever a iniciativa da GM Brasil em mudar o modo como faz os negócios na administração da cadeia de suprimentos.

A GM dispõe atualmente de 472 concessionárias autorizadas, 10 distribuidores, 9 oficinas autorizadas, 2 centros de distribuição (um em Sorocaba, outro em Mogi das Cruzes, São Paulo). Trabalhando com cerca de 75.000 itens de estoque, cerca de 700 itens são de alto giro, sendo o foco do trabalho desenvolvido pela montadora.

Observou-se que a demanda "bem comportada" do cliente final era uma demanda aos saltos para o fabricante, considerando-se 491 pontos de venda com gestão de estoques autônoma, liberando pedidos em quantidades e momentos diferentes. Nesta situação, a demanda percebida pelos centros de distribuição tornava-se oscilante de forma quase aleatória. Efetivamente o efeito Forrester mostrava-se preponderante na situação.

A General Motors, como elo forte de sua rede, disparou uma importante iniciativa de gestão de rede, em 1993, alguns anos depois da abertura do mercado brasileiro para veículos importados no Brasil. A GM passou a assumir a responsabilidade pela gestão de estoques das suas concessionárias, pois é o único player na rede que pode ver a demanda agregada e realizar previsões de vendas, respeitando particularidades regionais. Isto significa que a GM passou a sugerir quando, quais e quantos itens as concessionárias deveriam comprar.

Dado o relacionamento passado, seria possível que as concessionárias resistissem a esta idéia. Para superar esta resistência, a GM garante o fornecimento de produtos e proteção contra obsolescência, ou seja, permite às concessionárias revenderem para a GM qualquer produto que faz 
parte do acordo e que não apresente venda por um determinado período. Além disso, em caso de falta de algum artigo, a GM compromete-se a ter informações disponíveis às concessionárias na extranet sobre um "localizador de peças", isto é, a concessionária pode rapidamente obter a informação sobre onde a peça estaria disponível, entre os concessionários da redondeza.

No que se refere aos transportes, a GM utiliza o sistema "Milk Run": neste caso a freqüência de entregas é maior, reduzindo assim os estoques no ciclo e as cargas são consolidadas por região, o que impede o aumento de custo de fretes. $\mathrm{O}$ reabastecimento é feito 2, 3 ou 5 vezes por semana, dependendo do volume da demanda e localização do concessionário.

A sistemática de funcionamento é descrita no Quadro 2, de forma resumida:

\begin{tabular}{|c|l|}
\hline ETAPA & OPERACIONALIZAÇÃO DO VMI PELA GM BRASIL \\
\hline 1 & $\begin{array}{l}\text { A concessionária envia diariamente para GM um arquivo (via EDI) com informações sobre } \\
\text { vendas unitárias por produto (incluindo as vendas perdidas por indisponibilidade); }\end{array}$ \\
\hline 2 & $\begin{array}{l}\text { uma vez por semana o sistema recalcula o novo nível proposto de estoque máximo (por } \\
\text { concessionária e por item); }\end{array}$ \\
\hline 3 & $\begin{array}{l}\text { os gerentes de peças analisam os níveis máximos propostos, alterảndo-os, por exemplo, } \\
\text { quando ocorrem promoções por uma particular concessionária, para determinado item. } \\
\text { As informações são devolvidas para a montadora com os ajustes, conforme o caso; }\end{array}$ \\
\hline 4 & $\begin{array}{l}\text { durante a semana, o sistema GM recebe as posições de estoque e calcula as diferenças, } \\
\text { informando o Centro de Distribuição para reposição quando os estoques estão abaixo } \\
\text { do patamar acordado; }\end{array}$ \\
\hline 5 & $\begin{array}{l}\text { o CD envia uma notificação avançada para a concessionária, anunciando que um despacho } \\
\text { está a caminho (SKU / quant. / prazo); }\end{array}$ \\
\hline 6 & $\begin{array}{l}\text { ocorre o Picking / Packing no CD em São Paulo, identificação dos produtos e despacho } \\
\text { via sistema MILK RUN. }\end{array}$ \\
\hline
\end{tabular}

Quadro 2- Sistemática de funcionamento do VMI pela General Motors (fonte: dos autores).

A preocupação da GM não se limitou à sistemática ou refinamento dos algoritmos de cálculos estatísticos do software. Para implantação do sistema, inicialmente foram convidados os revendedores e varejistas para participação de um workshop oferecido pela GM. Na oportunidade, foram apresentadas as dificuldades geradas pelo bullwhip effect na cadeia de abastecimento e o conceito VMI, pelo PhD Henrique Corrêa.
Seguiu-se, então, a difícil fase de acordo, pois no passado ocorreram situações nas quais para um lado empresarial ganhar em uma negociação, o outro teve que perder. A adoção não foi imediata por todos, mas à medida que alguns revendedores aderiram ao programa, outros passaram a observar os ganhos com a redução de estoques e principalmente a substancial melhoria nos índices de capacidade de fornecimento. A partir de 
então, a entrada de outros distribuidores no programa foi tranqüila, quase que automática, uma vez que a iniciativa partia quase que dos próprios distribuidores e muito menos da montadora.

Com a adoção desta nova plataforma de trabalho, a GM espera aumentar a acuracidade das previsões de demanda (melhores modelos que os atuais), consideração de demandas nacionais e regionais, e aumento da disponibilidade de peças no ponto de venda, além de diminuir drasticamente os estoques, por causa da maior frequência de reabastecimento.

Antes da implantação deste esforço em coordenar a rede de suprimentos, uma pesquisa da GM mostrou que $80 \%$ do tempo dos gerentes das concessionárias era tradicionalmente gasto com o processo de aquisição de peças. Com o sistema automatizando, o foco passou para desenvolver o relacionamento com o cliente, buscar novas oportunidades de negócio e realmente vender.

\section{Exemplo de Passos no Comando da Cadeia}

Há cerca de 10 anos, a Rhodia, grupo mundial da área química, foi uma das primeiras empresas a lançar um serviço de entrega administrada.

Hoje, o sistema controla os estoques de fenol nos clientes de forma informatizada, via Internet. Vale ressaltar que neste caso há uma forte simplificação do sistema, pois, embora o fabricante controle os estoques do elo seguinte, não há intermediários entre estes estágios, como no caso da montadora de automóveis que dispõe de distribuidores regionais e revendas locais. $\mathrm{O}$ caso espelha-se no CFR (Continuous Replenishment Program), conhecido por reposição automática de insumos. Segundo Antonio S. Luvistto, gerente de negócios da empresa "os clientes não precisam mais se preocupar em controlar seus estoques, fazer programações de compra, formalizar pedidos e supervisionar a entrega do produto".

Para observar o foco do distribuidor, um bom exemplo é do grupo Sonae que adotou o sistema VMI com cinco fornecedores, segundo o diretor de logística da empresa, Antonio Freitas, em declaração à revista LOG\&MAN em abril de 2003: "com a implantação do VMI, reduzimos $o$ indice de erros e aumentamos a produtividade $e$ as vendas, mas o mais importante foi a melhoria no relacionamento entre a Sonae e seus fornecedores principais".

A integração da cadeia de suprimentos passa pelo desenvolvimento de um esforço coordenado de previsão de vendas entre fabricantes e seus fornecedores, atacadistas e varejistas. É importante observar que VMI não significa transferência de responsabilidade. Embora um player da cadeia passe a assumir o controle de estoques dos elos a jusante da corrente, as responsabilidades são compartilhadas, ou seja, os ganhos e a solução de problemas devem ser tratados de forma conjunta pelos estágios da rede de abastecimento.

\section{O Poder da Informação e a Perspectiva de Futuro}

Chopra \& Meindl afirmam que "o compartilhamento de informações precisas e confiáveis por todos os elos resulta em melhor sincronia entre oferta e demanda e em custos menores" (CHOPRA \& MEINDL, 2001). Esta transparência de informações conduz a um bom relacionamento entre os estágios da rede, reduzindo o custo de transações e a duplicidade de tarefas, colaborando assim para sanar o problema do efeito chicote.

Tradicionalmente, o fluxo de informações está associado ao fluxo de produtos. Com os atuais recursos de comunicação, ocorreu uma ruptura entre o fluxo de produtos físicos e o respectivo fluxo de informações. O surgimento de diversas tecnologias de comunicação, com padrões técnicos que permitem a comunicação de todos em qualquer lugar e a baixo custo, está causando esta revolução. Estes fatores indicam que com o e-commerce o mercado pode ficar concentrado nas mãos de poucos (mas poderosos) players. No entanto, as organizações atuais estão sendo impedidas de alavancar níveis mais altos de eficiência, devido à atividade de distribuição. Possuir capacidade no que diz respeito à atividade de logística mostra-se vital para os negócios.

Ressalva-se que regimes de fornecimento, como ECR, não eliminam a necessidade de pre- 
visão de vendas por parte dos fabricantes e fornecedores de insumos. A transmissão em tempo real do consumo ocorrido na ponta da cadeia, apenas sinaliza para o fabricante sobre a reposição de produtos. A aquisição de insumos e a programação da produção no fabricante são decisões que ainda dependem de previsões de venda para serem tomadas, especialmente se os lead times forem significativamente maiores que um dia. Obviamente, o fabricante realizará previsões de vendas muito mais apuradas com base nos dados atualizados de consumo de seu produto no varejista, porém apenas a transmissão em tempo real dos dados não viabiliza o conceito VMI.

A Internet, além de ser um canal direto com os consumidores e todos os demais integrantes da cadeia de suprimento, é um recurso para a realização de inovações. As organizações procuram buscar outras estratégias que lhes permitam conquistar vantagens competitivas, às vezes mudando a lógica de relacionamento na cadeia de valores. Logo, "é possível buscar alternativas de criação de valor e não apenas capturar valor de outras empresas" (CORREA, ET. AL., 2001).

\section{Conclusão}

As organizações em rede se desenvolvem especialmente em setores maduros e de uso intenso de mão de obra, com a ajuda da tecnologia de informação. A aceleração de seu clockspeed acirrou a competição e mudou a estrutura de poder por toda a rede de fornecimento. Os grandes varejistas e produtores modelam suas redes de fornecimento, oferecendo produtos de alta qualidade para consumidores de necessidades específicas.

A concorrência do futuro será mais centrada na competição entre coalizões de empresas do que entre empresas em particular. Os motivos para que coalizões se formem podem ser que as empresas, isoladamente, não possuem todas as habilidades possíveis necessárias para competir.

A falta de coordenação ocorre quando cada elo da cadeia de suprimento otimiza apenas seu próprio objetivo, sem considerar seu impacto na cadeia inteira. Esta postura poderá levar à "soma vetorial zero". O VMI permite que o fabricante aumente seus lucros e os da cadeia de abastecimento como um todo.

Conforme exposto no estudo de caso, as escolhas feitas pela GM representam uma ruptura com seu passado e, de certa forma, uma divergência com as práticas do setor. Seu esforço na coordenação da rede de suprimentos, as reduções dos inventários com o aumento simultâneo nos níveis de disponibilidade de partes e peças, e, portanto, melhores níveis de serviço ao cliente final, só foram possíveis de serem atingidos devido à fluidez nas comunicações, maior transparência nos negócios e mudança radical de postura dos players, especialmente, e, sobretudo, da própria montadora, elo forte da cadeia de abastecimento. Esta mudança representa uma alternativa para tornar mais fortes outras organizações em rede.

Paradoxalmente, é possível ter maior flexibilidade externa a partir de estrutura organizacional mais rígida, controle rigoroso da cadeia de fornecimento e exploração completa das transformações locais.

Diversas medidas de melhoria de desempenho são levadas a cabo pelos gestores na busca da redução de custos de fabricação, custos de estoque, lead time de ressuprimento, custos de transporte, custo de mão de obra e aumento do nível de disponibilidade do produto na periferia da cadeia de suprimentos. De todas as ações, uma das mais importantes é a melhoria no relacionamento dos players. É preciso projetar soluções eficazes para os conflitos e, neste momento, a mudança de postura é pedra fundamental, de modo a promover a transparência e construir uma base sólida de cooperação e confiança mútua entre os elos.

No ambiente de hoje (e do futuro), não basta mais para uma empresa ser excelente na gestão exclusiva de seus recursos, pois para ter sucesso sustentável é necessário que haja uma gestão coesa na rede à qual pertence, para que o cliente final possa tornar-se satisfeito, fiel e recompensar a rede com seu retorno. 


\section{REFERÊNCIAS BIBLIOGRÁFICAS}

ANDRADE, Aurélio L. "Pensamento Sistêmico: um roteiro básico para perceber as estruturas da realidade organizacional". Revista Tecnologística. São Paulo, 2000.

BOWERSOX, Donald J. \& CLOSS, David J. Logística Empresarial: o processo de integração da cadeia de suprimento. São Paulo: Atlas, 2001.

CHOPRA, Sunil; MEINDL, Peter. Gerenciamento da Cadeia de Suprimentos: Estratégia, Planejamento e Operações. São Paulo: Prentice Hall, 2003.

CORRÊA, Henrique L General Motors Brasil Service Business. Disponível na Internet:<http://www.correa.com.br/biblioteca/ casos/C02_Estudo_de_caso_AUTO_GIRO_Revisado.pdf >. Acesso em: 13 abr 2004. (2001).

CORREAA, Henrique L.; GIANESI, Irineu Gustavo; CAON, Mauro. Planejamento, Programação e Controle da Produção. São Paulo: Atlas, 2001.

DORNIER, Philippe-Pierre et al. Logística de Operações Globais. São Paulo: Atlas, 2000.

FLEURY, Paulo F; WANKE, Peter; FIGUEIREDO, Kleber F. Logística Empresarial: a perspectiva brasileira. São Paulo: Atlas, 2000.

FORRESTER, Jay W. The Beginning of Systems Dynamics. Banquet Talk at the International Meeting of the Systems Dynamics Society Stuttgart. Germany, July 13, 1989.

FREITAS, Antonio. “Estratégias para o Sucesso do V.M.I." Revista LogĖMan. São Paulo, p. 46-47, abril, 2003.

VINELLI, Andréa.; ROMANO, Pietro; CAMUFFO, Arnaldo. "De Volta para o Futuro: Grupo Benetton”. HSM Management. maio/2002.

LEE, Hau L.; PADMANABHAN, V; WANG, Seungjin. "The Bullwhip effect in supply chains". Sloan Management Review, 93-103, 1997. Disponível na Internet em: < http://teaching.ust.hk/ ieem341/papers/Lee97.pdf>. Acesso em: 13 abr 2004.

LUVIZETO, Antonio S. "Estoques sob Controle”. Revista Tecnologística. São Paulo, p. 16-17, mar 2003.

SAGGIORO, Eduardo; LACERDA, Leonardo; AROZO, Rodrigo. "Gerenciando Incertezas no Planejamento Logístico: O Papel do Estoque de Segurança”. Revista Tecnologística. São Paulo, p. 46, fev 2001.

SLACK, Niguel et al. Administração da Produção. São Paulo: Atlas, 2002. 